\title{
Influence of thermal and mass transfer, the properties of steam-oxygen oxidizer and structure of coke on the composition of the generating synthesis-gas at the gasification of fuel
}

\author{
Roman N. Aryukov ${ }^{1}$, Alexander N. Subbotin ${ }^{1, *}$ \\ ${ }^{1}$ National Research Tomsk Polytechnic University, 634050 Tomsk, Russia
}

\begin{abstract}
A mathematical model of the solid fuel conversion process which is used to analyze the synthesis-gas that is the result of coke gasification is proposed. During the conversation of coke in an environment of high-temperature water vapor, synthesis-gas consisting of hydrogen, oxide and carbon dioxide is obtained. That is shown in the article. Hydrogen in the produced gas at any oxidizer temperatures is always over $50 \%$ of total volume. The ratio of oxide and carbon dioxide depends on the temperature of the oxidant. The lower the oxidant temperature, the greater the proportion of carbon monoxide. It is established that it is economically more advantageous to use water vapor with the addition of oxygen as an oxidizer in the gasification of fuel. With the use of such an oxidizer, synthesis-gas consisting of $100 \%$ of the combustion gas is obtained. The temperature of the steam-oxygen oxidant after the fuel has ignited can be significantly reduced practically before the beginning of the process of vapor condensation. The synthesis-gas produced in this gasification process will contain in volume proportions about $25 \%$ hydrogen and $75 \%$ carbon monoxide.
\end{abstract}

\section{Introduction}

Solid fuel in the total amount of fuel consumed in the energy sector takes a significant share. In particular, in Europe and the US, coal accounts for about $60 \%$ of the energy sector. In the energy sector of Russia, the use of coal is approximately $18 \%$. According to the development strategy of the Russian coal industry, it is planned to significantly increase the export of coal for the coke-chemical industry. Such an increase in coal production and planned exports will lead to an even greater increase in accumulated waste, which, as a rule, consists of slimes and fines. Burning of these wastes is ineffective, since their ash content is high, up to $50 \%$ and higher.

${ }^{*}$ Corresponding author: $\underline{\text { subbot@tpu.ru }}$ 
The universal method of processing such wastes is their gasification. In modern gas generators, as a rule, steam-air or steam-oxygen blowing is used. This technology has both advantages and disadvantages. In particular, the disadvantages include the content of ballast admixtures in the synthesis gas, the part of the carbon burns in the gas generator. In connection with this the creation of a mathematical model of a gasifier for the conversion of solid fuels in an environment of various oxidants is an urgent task. Such a mathematical model can serve as a tool for estimating the composition of gasification products and for finding the optimal regimes for the gasification process.

\section{Mathematical formulation of the problem}

We consider a cylindrical capsule filled with coke, through which a heated steam heated up to a high temperature or a steam-oxygen oxidizer is pumped. In accordance with the work [1] and proceeding from experimental studies conducted at the department of the Kuzbass State Technical University [2], the following chemical reactions were considered:

$$
\begin{gathered}
\mathrm{C}+\mathrm{H}_{2} \mathrm{O}=\mathrm{CO}+\mathrm{H}_{2}-130.5 \mathrm{~kJ} / \mathrm{mol}, \\
\mathrm{C}+\mathrm{CO}_{2}=2 \mathrm{CO}-175.5 \mathrm{~kJ} / \mathrm{mol}, \\
\mathrm{C}+\mathrm{O}_{2}=\mathrm{CO}_{2}+395 \mathrm{~kJ} / \mathrm{mol}, \\
2 \mathrm{C}+\mathrm{O}_{2}=2 \mathrm{CO}+219 \mathrm{~kJ} / \mathrm{mol}, \\
2 \mathrm{H}_{2}+\mathrm{O}_{2}=2 \mathrm{H}_{2} \mathrm{O}+219 \mathrm{~kJ} / \mathrm{mol}, \\
2 \mathrm{CO}+\mathrm{O}_{2}=2 \mathrm{CO}_{2}+571 \mathrm{~kJ} / \mathrm{mol}, \\
\mathrm{CO}+\mathrm{H}_{2} \mathrm{O}=\mathrm{CO}_{2}+\mathrm{H}_{2}+40.4 \mathrm{~kJ} / \mathrm{mol}
\end{gathered}
$$

Research objective: The determination of the synthesis-gas in the conversion of coke, the analysis of the composition of the gas formed, depending on the conditions of heat and mass transfer, the structure of the coke sample under study and the properties of the oxidant.

The simulation of the non-stationary mode of heat and mass transfer during coke conversion was carried out on the basis of the mathematical model [3]. It was assumed that there was no free moisture in the pores during the conversion, then the volume fraction of moisture $\left(\varphi_{2}\right)$ is zero, and since the coke was considered, the volume fraction of solid fuel $\left(\varphi_{1}\right)$ is also zero. Therefore, according to [3] and the reactions (1) we have the following system of equations:

- conservation of coke mass

$$
\rho_{3} \cdot \frac{\partial \varphi_{3}}{\partial \tau}=-R_{C}, \quad R_{C}=R_{C 1}+R_{C 2}+R_{C 3}+R_{C 4}
$$

- continuity of the gas phase

$$
\frac{\partial \rho_{5} \varphi_{5}}{\partial \tau}+v \cdot \frac{\partial \rho_{5} \varphi_{5}}{\partial z}=R_{C}
$$

- continuity $\alpha$-of the gas phase component

$$
\frac{\partial\left(\rho_{5} \varphi_{5} c_{\alpha}\right)}{\partial \tau}+v \frac{\partial\left(\rho_{5} \varphi_{5} c_{\alpha}\right)}{\partial z}=\frac{\partial}{\partial z}\left(\rho_{5} \varphi_{5} D_{\alpha} \frac{\partial c_{\alpha}}{\partial z}\right)+R_{5 \alpha}+R_{S \alpha}, \alpha=\overline{1,4}
$$


here parameter with an index $\alpha=1$ corresponds to the oxygen $\left(\mathrm{O}_{2}\right), \alpha=2-\mathrm{CO}, \alpha=3-$ $\mathrm{CO}_{2}, \alpha=4-\mathrm{H}_{2}, \alpha=5-\mathrm{H}_{2} \mathrm{O}$;

- conservation of energy of the gas phase

$$
\begin{aligned}
& \rho_{5} \varphi_{5} c_{P 5}\left(\frac{\partial T}{\partial \tau}+v \cdot \frac{\partial T}{\partial z}\right)=\frac{\partial}{\partial z}\left(\left(\lambda_{5}+\lambda_{R}\right) \varphi_{5} \frac{\partial T}{\partial z}\right)-A_{s}\left(T-T_{S}\right) \\
& +q_{C O}^{1} R_{C O}^{1}+q_{C O}^{2} R_{C O}^{2}+q_{H_{2}} R_{H_{2}}-\frac{2}{r_{o}} \alpha_{1} \varphi_{5}\left(T-T_{S}\right) ;
\end{aligned}
$$

- conservation of energy of the condensed phase (coke)

$$
\begin{aligned}
& \sum_{i=3}^{4} \rho_{i} \varphi_{i} c_{p_{i}} \frac{\partial T_{S}}{\partial \tau}=\frac{\partial}{\partial z}\left(\lambda_{S} \frac{\partial T_{S}}{\partial z}\right)+q_{C 1} R_{C 1}+q_{C 2} R_{C 2}-q_{C 3} R_{C 3}-q_{C 4} R_{C 4}+ \\
& A_{S}\left(T-T_{S}\right)+\frac{2 \cdot r_{1}}{r_{0}^{2}} \alpha_{2}\left(T_{S}-T_{E}\right)+q_{R} ;
\end{aligned}
$$

- the gas motion in the pores (in the form of a quadratic filtration law) and the equation of state

$$
v=\frac{k}{\mu+k \cdot \beta \cdot \rho_{5} \cdot V \mid} \cdot \frac{\partial p}{\partial z}, \quad p=\frac{\rho_{5} \cdot R \cdot T}{M_{5}} .
$$

The system of equations (2) - (7) was solved under the boundary conditions:

$$
\begin{array}{ll}
\tau=0: & \varphi_{i}=\varphi_{i H}, i=\overline{3,4} ; \quad c_{\alpha}=c_{\alpha H}, \alpha=\overline{1,4}, \quad T=T_{S}=T_{H}, \quad p=p_{H} ; \\
\mathrm{z}=0: \quad T=T_{G}, \quad(p v)_{w}=\text { const }, \quad \lambda_{S} \cdot \frac{\partial T_{S}}{\partial z}=\alpha_{1} \cdot\left(T_{S}-T_{G}\right), \quad c_{\alpha}=c_{\alpha G}, \\
\mathrm{z}=\mathrm{h}: \quad \frac{\partial c_{\alpha}}{\partial z}=\frac{\partial T}{\partial z}=0, \quad p=p_{H}, \quad \lambda_{S} \frac{\partial T_{S}}{\partial z}=0 .
\end{array}
$$

In the equations (2)-(7) the following notation is introduced: $c_{p_{5}}=\sum_{\alpha=1}^{5} c_{p_{\alpha}} c_{\alpha}$, $\lambda_{S}=\sum_{i=3}^{4} \lambda_{i} \varphi_{i}, \quad \lambda_{R}=\frac{16 \sigma T^{3}}{s}, \quad M_{5}=1 / \sum_{\alpha=1}^{7} \frac{c_{\alpha}}{M_{4 \alpha}}, \quad R_{\mathrm{C} 1}=s \rho_{5} \varphi_{5} c_{7} k_{S 1} \varphi_{3} \exp \left(\frac{-E_{\mathrm{C} 1}}{R \cdot T_{S}}\right)$, $R_{\mathrm{CO}}^{2}=k_{\mathrm{CO}}^{2}\left(c_{1} M / M_{51}\right)^{0.25}\left(c_{2} M / M_{52}\right) \cdot T^{-2.25} \exp \left(\frac{-E_{\mathrm{CO}}^{2}}{R \cdot T}\right), \quad R_{\mathrm{C} 2}=s \rho_{5} \varphi_{5} c_{3} k_{S 2} \varphi_{3} \exp \left(\frac{-E_{\mathrm{C} 2}}{R \cdot T_{S}}\right)$, $R_{\mathrm{C} 3}=s \rho_{5} \varphi_{5} c_{1} k_{S 3} \varphi_{3} \exp \left(\frac{-E_{\mathrm{C} 3}}{R \cdot T_{S}}\right), \quad R_{\mathrm{CO}}^{1}=k_{\mathrm{CO}}^{1} c_{2} c_{7} \exp \left(\frac{-E_{\mathrm{CO}}^{1}}{R \cdot T}\right), \quad R_{\mathrm{H}_{2}}=k_{\mathrm{H}_{2}} c_{1} c_{4} \cdot \exp \left(\frac{-E_{\mathrm{H}_{2}}}{R \cdot T}\right)$, $R_{52}=\gamma_{5} R_{C 1}+\gamma_{6} R_{C 2}+\gamma_{7} R_{C 4}, \quad R_{54}=\gamma_{13} R_{\mathrm{C} 1}+\gamma_{14} R_{\mathrm{CO}}^{1}-\gamma_{15} R_{\mathrm{H}_{2}}, \quad R_{57}=\gamma_{16} R_{\mathrm{H}_{2}}-\gamma_{17} R_{\mathrm{C} 1}-\gamma_{18} R_{\mathrm{CO}}^{1}$, $R_{51}=-\left(\gamma_{1} R_{\mathrm{C} 2}+\gamma_{2} R_{\mathrm{C} 3}+\gamma_{3} R_{\mathrm{H}_{2}}+\gamma_{4} R_{\mathrm{CO}}^{2}\right), \quad R_{53}=\gamma_{8} R_{\mathrm{C} 3}-\gamma_{10} R_{\mathrm{C} 2}+\gamma_{11} R_{\mathrm{CO}}^{1}+\gamma_{12} R_{\mathrm{CO}}^{2}$, $R_{\mathrm{C} 4}=s \rho_{5} \varphi_{5} c_{1} k_{S 4} \varphi_{3} \exp \left(\frac{-E_{\mathrm{C} 4}}{R \cdot T_{S}}\right)$. All other notations coincide with the notation introduced in $[3,4$ and 6]. 


\section{Analysis of numerical results}

The comparison of experimental and numerical studies [5] showed that good agreement on the percentage content of gasification products after sample heating is achieved. The temperature in the sample layer, found numerically, also agrees with the results of laboratory studies. Thus, this mathematical model adequately simulates the process under investigation and can be used for analysis of the gas composition when studying the processes of conversion of organic fuel. The values of thermophysical and kinetic properties at which numerical calculations were performed are given in $[3,4]$.

With the help of the mathematical model proposed above, studies of the yield of synthesis gas depending on the temperature of the supplied vapor $\left(T_{\mathrm{G}}\right)$, on the initial porosity and the specific surface of pores of the gasified solid fuel (coke) were conducted. The results of all numerical calculations for different values of porosity, specific surface of pores and three values of the temperature of the blown oxidant (water vapor) are given in tables 1, 2, 3 .

In Tables $\varphi_{5 \mathrm{H}}$ - initial porosity of coke, $S_{*}$ - specific surface of pores. The set of these two parameters determine the structure of coke. Analyzing the results presented in Tables, we come to the conclusion that as the porosity decreases at any specific surface area of the pores $S_{*}$ the fraction of $\mathrm{CO}$ in the synthesis gas decreases, and the fraction of $\mathrm{CO}_{2}$ and $\mathrm{H}_{2}$ increases.

Table 1. Composition of synthesis gas at a water vapor temperature $T_{\mathrm{G}}=873 \mathrm{~K}$.

\begin{tabular}{|c|c|c|c|c|}
\hline$\varphi_{5 \mathrm{H}}$ & $\begin{array}{c}\text { Volumetric composition of } \\
\text { gas synthesis, } \%\end{array}$ & $S_{*}=5 \cdot 10^{2}, 1 / \mathrm{m}$ & $S_{*}=5 \cdot 10^{3}, 1 / \mathrm{m}$ & $S_{*}=5 \cdot 10^{4}, 1 / \mathrm{m}$ \\
\hline \multirow{3}{*}{0.9} & $\mathrm{CO}$ & 41.5 & 46.9 & 51.2 \\
\cline { 2 - 5 } & $\mathrm{CO}_{2}$ & 6.0 & 1.7 & 0.3 \\
\cline { 2 - 5 } & $\mathrm{H}_{2}$ & 52.5 & 51.4 & 48.5 \\
\hline \multirow{3}{*}{0.5} & $\mathrm{CO}$ & 39.3 & 45.2 & 47.1 \\
\cline { 2 - 5 } & $\mathrm{CO}_{2}$ & 6.4 & 2.4 & 1.0 \\
\hline \multirow{3}{*}{0.1} & $\mathrm{H}_{2}$ & 54.3 & 52.4 & 51.9 \\
\cline { 2 - 5 } & $\mathrm{CO}_{2}$ & 35.4 & 42.1 & 44.6 \\
\cline { 2 - 5 } & $\mathrm{CO}_{2}$ & 10.0 & 3.8 & 53.7 \\
\hline
\end{tabular}

Analyzing the results given in the tables, it can be concluded that when the fuel is converted, the yield of the gas composition depends significantly less on the porosity than on the specific surface of the pores.

Table 2. Composition of synthesis gas at a water vapor temperature $T_{\mathrm{G}}=1173 \mathrm{~K}$.

\begin{tabular}{|c|c|c|c|c|}
\hline \multirow{2}{*}{$\varphi_{5 \mathrm{H}}$} & $\begin{array}{c}\text { Columetric } \\
\text { composition of gas } \\
\text { synthesis, } \%\end{array}$ & $S_{*}=5 \cdot 10^{2}, 1 / \mathrm{m}$ & $S_{*}=5 \cdot 10^{3}, 1 / \mathrm{m}$ & $S_{*}=5 \cdot 10^{4}, 1 / \mathrm{m}$ \\
\hline \multirow{3}{*}{0.9} & $\mathrm{CO}$ & 7.4 & 37.0 & 47.8 \\
\cline { 2 - 5 } & $\mathrm{CO}_{2}$ & 27.2 & 6.9 & 0.6 \\
\cline { 2 - 5 } & $\mathrm{H}_{2}$ & 65.4 & 56.1 & 51.6 \\
\hline \multirow{3}{*}{0.5} & $\mathrm{CO}$ & 3.2 & 28.5 & 44.9 \\
\cline { 2 - 5 } & $\mathrm{CO}_{2}$ & 29.3 & 11.8 & 2.3 \\
\cline { 2 - 5 } & $\mathrm{H}_{2}$ & 67.5 & 59.7 & 52.8 \\
\hline \multirow{3}{*}{0.1} & $\mathrm{CO}^{*}$ & 1.4 & 184 & 37.6 \\
\cline { 2 - 5 } & $\mathrm{CO}_{2}$ & 29.2 & 16.3 & 56.2 \\
\cline { 2 - 5 } & $\mathrm{H}_{2}$ & 69.4 & 65.3 & \\
\hline
\end{tabular}


It also should be noted that for the same porosity, the composition of the gas is strongly dependent on the specific surface area of the pores (pore size). If the pores are very small $\left(S_{*}=5 \cdot 10^{4}, 1 / \mathrm{m}\right)$, the synthesis gas by more than $90 \%$ will consist of carbon monoxide and hydrogen. For samples with big pores $\left(S_{*}=5 \cdot 10^{2}, 1 / \mathrm{m}\right)$ the resulting synthesis gas will have about $30 \%$ of carbon dioxide and about $70 \%$ of hydrogen and a negligible amount of CO (Tables 2 and 3 ).

It should be noted that during gasification of coke in a water vapor environment, the proportion of combustion gas in the gasification products is the higher, the higher the oxidant temperature. In particular, at an oxidizer temperature of $873 \mathrm{~K}$ the carbon dioxide fraction is the lowest (less than 10\%) for any porosity and specific surface area of the pores. Numerical calculations have shown that the method of gasification using high-temperature water vapor is not economically profitable. Because even at the temperature of the supplied steam of $1473 \mathrm{~K}$, the volume fraction of the combustion gas at the outlet from the gasifier is only about $3 \%$ and $97 \%$ is water vapor.

Table 3. Composition of synthesis gas at a water vapor temperature $T_{\mathrm{G}}=1473 \mathrm{~K}$.

\begin{tabular}{|c|c|c|c|c|}
\hline \multirow{2}{*}{$\varphi_{5 \mathrm{H}}$} & $\begin{array}{c}\text { Volumetric } \\
\text { composition of gas } \\
\text { synthesis, } \%\end{array}$ & $S_{*}=5 \cdot 10^{2}, 1 / \mathrm{m}$ & $S_{*}=5 \cdot 10^{3}, 1 / \mathrm{m}$ & $S_{*}=5 \cdot 10^{4}, 1 / \mathrm{m}$ \\
\hline \multirow{3}{*}{0.9} & $\mathrm{CO}$ & 1.3 & 21.5 & 43.4 \\
\cline { 2 - 5 } & $\mathrm{CO}_{2}$ & 30.5 & 15.6 & 1.8 \\
\cline { 2 - 5 } & $\mathrm{H}_{2}$ & 68.2 & 62.9 & 54.8 \\
\hline \multirow{3}{*}{0.5} & $\mathrm{CO}$ & 0.5 & 14.9 & 41.8 \\
\cline { 2 - 5 } & $\mathrm{CO}_{2}$ & 30.7 & 18.7 & 3.8 \\
\cline { 2 - 5 } & $\mathrm{H}_{2}$ & 68.8 & 66.4 & 34.4 \\
\hline \multirow{3}{*}{0.1} & $\mathrm{CO}^{*}$ & 0.3 & 12.2 & 8.9 \\
\cline { 2 - 5 } & $\mathrm{CO}_{2}$ & 30.3 & 19.6 & 57.4 \\
\cline { 2 - 5 } & $\mathrm{H}_{2}$ & 69.4 & 68.2 & \multicolumn{2}{c}{} \\
\hline
\end{tabular}

At an oxidizer temperature of $873 \mathrm{~K}$, water vapor is $99 \%$, and combustion gases are only $1 \%$. Therefore, the resulting combustion gases are not enough even for heating to the desired temperature of the oxidant. In connection with this, further studies on gasification were carried out in an oxidizer environment consisting of water vapor and oxygen.

Table 4 presents the results of calculating the coke gasification in a steam-oxygen oxidant environment with the same initial porosity as for pure water vapor, the mass concentration of oxygen was 0.4 and the mass concentration of water vapor was 0.6.

Table 4. The composition of the synthesis gas produced at the initial oxidant temperature $T_{\mathrm{G}}=873 \mathrm{~K}$.

\begin{tabular}{|c|c|c|c|c|}
\hline \multirow{2}{*}{$\varphi_{5 \mathrm{H}}$} & $\begin{array}{c}\text { Volumetric } \\
\text { composition of gas } \\
\text { synthesis, } \%\end{array}$ & $S_{*}=5 \cdot 10^{2}, 1 / \mathrm{m}$ & $S_{*}=5 \cdot 10^{3}, 1 / \mathrm{m}$ & $S_{*}=5 \cdot 10^{4}, 1 / \mathrm{m}$ \\
\hline \multirow{3}{*}{0.9} & $\mathrm{CO}$ & 72 & 75.3 & 76 \\
\cline { 2 - 5 } & $\mathrm{H}_{2}$ & 25 & 24.5 & 24 \\
\cline { 2 - 5 } & $\mathrm{CO}_{2} / \mathrm{O}_{2}$ & $0.4 / 2.6$ & $0.05 / 0.15$ & $0 / 0$ \\
\hline \multirow{3}{*}{0.5} & $\mathrm{CO}$ & 731 & 75.8 & 76.2 \\
\cline { 2 - 5 } & $\mathrm{H}_{2}$ & 26.8 & 24.2 & 23.8 \\
\cline { 2 - 5 } & $\mathrm{CO}_{2} / \mathrm{O}_{2}$ & $0.1 / 0$ & $0 / 0$ & $0 / 0$ \\
\hline \multirow{3}{*}{0.1} & $\mathrm{CO}$ & 73.5 & 75.1 & 76.6 \\
\cline { 2 - 5 } & $\mathrm{H}_{2}$ & 26.5 & 24.9 & 23.4 \\
\cline { 2 - 5 } & $\mathrm{CO}_{2} / \mathrm{O}_{2}$ & $0 / 0$ & $0 / 0$ & $0 / 0$ \\
\hline
\end{tabular}

Analyzing the results given in Table 4, we come to the conclusion that irrespective of the porosity and specific surface of the pores in the steam-oxygen gasification, we obtain a 
combustion gas consisting in volume approximately by $(23-27) \%$ of hydrogen and by (7773) $\%$ of carbon monoxide A small amount of oxygen and carbon dioxide remains unreacted for samples with large porosity and (or) a small specific surface of the pores. It should be noted that under these gasification conditions, water vapor reacts completely, and there is no need to separate the vapor from the gasification products. From the reactor comes carbon monoxide diluted in volume by about a quarter by hydrogen. In some cases (with a large porosity of gasified fuel), a small amount of carbon dioxide and not consumed oxygen appears.

The results on the effect of the proportion of oxygen in the oxidant on the composition of synthesis gas are presented in Table 5. Analyzing the data in the table, we come to the conclusion that when the mass concentration of oxygen $C_{1}$ varies from 0.1 to 0.3 and the mass concentration of water vapor $C_{5}$ varies from 0.9 to 0.7 , the volumetric composition of synthesis gas varies rather weakly, the maximum temperature of the gasification process increases quite strongly, especially the temperature of the coke. Therefore, by changing the oxidizer composition, it is possible to control the gasification temperature and consequently the conversion rate of the coke. The composition of the resulting synthesis gas will vary slightly in this case.

Table 5. The gas composition and temperature of the gasification products at different ratios of oxygen and water vapor in the oxidizer $\left(\varphi_{5 \mathrm{H}}=0.1, S_{*}=5 \cdot 10^{4}, 1 / \mathrm{m}\right)$.

\begin{tabular}{|c|c|c|c|c|c|c|}
\hline \multicolumn{2}{|c|}{$\begin{array}{c}\text { The composition of the } \\
\text { oxidizer } C_{1} / C_{5}\end{array}$} & $0.1 / 0.9$ & $0.15 / 0.85$ & $0.2 / 0.8$ & $0.25 / 0.75$ & $0.3 / 0.7$ \\
\hline $\begin{array}{c}\text { Volumetric composition } \\
\text { of gas synthesis, } \%\end{array}$ & $\mathrm{CO}$ & 61.7 & 62.5 & 65.9 & 67.8 & 70.5 \\
\cline { 2 - 8 } & $\mathrm{H}_{2}$ & 38.3 & 37.5 & 34.1 & 32.2 & 29.5 \\
\hline Maximum temperature, $\mathrm{K}$ & gas & 1216 & 1356 & 1586 & 1723 & 1907 \\
\cline { 2 - 7 } & coke & 1250 & 1527 & 2038 & 2368 & 2753 \\
\hline
\end{tabular}

In addition to the results presented above, studies of the influence of the initial temperature of the oxidizer on the gasification process were carried out. Figure 1 shows the distribution of temperature in the coke along the depth of the fuel for three values of the initial temperature of the oxidizer. Distribution 1 was obtained at an initial oxidant temperature of $873 \mathrm{~K}$.

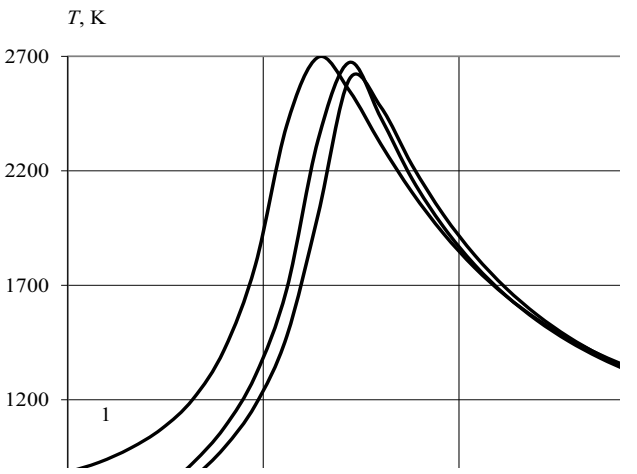

Fig. 1. Temperature profiles in coke at different initial oxidizer temperatures.

If the initial temperature of the oxidizer is further reduced, the temperature profile will move to the right (Fig. 1, curve 2). The maximum temperature will decrease slightly, and the profile will shift deep into the gasified fuel. If the oxidizer temperature drops to $373 \mathrm{~K}$, the maximum temperature will slightly decrease and shift to the right (Fig. 1, curve 3 ). In all three cases, the composition of the synthesis gas produced is practically the same. 
Consequently, after the coke has ignited and the gasification process has begun, the oxidizer temperature can be reduced to a minimum.

\section{Conclusions}

Based on the numerical calculations performed, the following conclusions can be drawn: the formulated mathematical model describes the process of conversion of solid fuel with sufficient accuracy for practice and it can be used to predict the composition of synthesisgas in the gasification of solid fuels. During steam gasification the change in the temperature of the oxidizer, the speed of its supply and the porosity of the fuel affect the composition of the combustion gas formed. The temperature of the oxidizer exerts the greatest influence on the yield of synthesis gas during steam gasification.

In the case of steam-oxygen gasification, the influence of the fuel structure (porosity and specific surface of the pores) is small. The determining parameter of the process is the proportion of oxygen in the oxidant. By changing it, different regimes can be obtained, both in speed and in gasification temperature.

\section{References}

1. V.V. Pomerantsev, K.M. Arefyev and others, Bases of the practical theory of burning: the Manual for high schools (Energoatomizdat, Moscow, 1986) [in Russian]

2. S.A. Shevyrev, A.R. Bogomolov, Power system, 12, 33 (2013)

3. A.N. Subbotin, News of Tomsk polytechnic university, 4, 23 ( 2008)

4. R.N. Kulesh, A.S. Mazanik, A.N. Subbotin, News of Tomsk polytechnic university, 4, 25 (2014)

5. A.N. Subbotin, S.A. Shevyrev, News of Tomsk Polytechnic University, 4, 107(2012)

6. R.N. Aryukov, A.N. Subbotin, MATEC Web Conf. 72, (2016) 